\section{DGMM-Vorstandsmitglieder stellen sich vor}

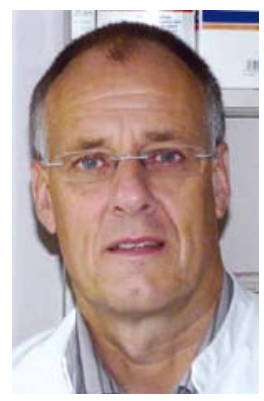

Dr. med. Jens Kohfahl, Jahrgang 1954, ist seit 2010 Beisitzer im Vorstand der DGMM.

Er studierte Medizin von 1977-1983 in Köln und Hannover und war von 1983-1990 Assistenzarzt in Bremerhaven und Cuxhaven in den Fächern Pathologie, Innere Medizin, Chirurgie und Allgemeinmedizin. Von 1990-2006 war Dr. Kohfahl Mitarbeiter beim Hafenärztlichen Dienst des Landkreises Cuxhaven. Von 2006-2008 leitete er die Arbeitsgruppe Medizin bei der DGzRS bis zu deren Auflösung.

Dr. Kohfahl ist Facharzt für Allgemeinmedizin mit den Zusatzbezeichnungen: Betriebsmedizin, Notfallmedizin, Sportmedizin sowie Tauchmedizin (nach GTÜM).

Er ist:

- Seit 1987 Notarzt im Rettungsdienst der Stadt Cuxhaven und tätig als „Seenotarzt“ für den in Cuxhaven stationierten Rettungskreuzer der DGzRS (Deutsche Gesellschaft zur Rettung Schiffbrüchiger).

- Seit 1987 ärztlicher Berater für die DGzRS in den Bereichen Ausbildung des seemännischen Rettungspersonals in Erster Hilfe, Überleben auf See sowie medizinische Ausrüstung der Rettungskreuzer.

- Seit 2002 Leitender Notarzt im Rettungsdienst der Stadt Cuxhaven und in dieser Funktion auch tätig in einem Verletztenversorgungsteam (VVT) für das Havariekommando.

- Seit 2003 Mitarbeiter beim Havariekommando in der Ausbildung von Notärzten für den Einsatz auf See.

- Seit 2007 Taucherarzt der DLRG in Cuxhaven.

- Seit 2009 Ärztlicher Fachberater des Havariekommandos.

Weiterhin ist Dr. Kohfahl Mitautor des Buches „Medizin auf See“ (erschienen im Delius Klasing Verlag).

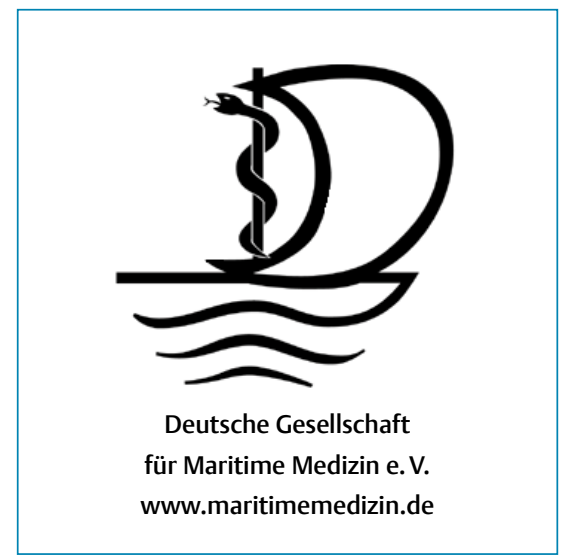

23. und 24. November 2012 im Ostfriesischen Landesmuseum Emden

Die medizinischen Versorgungsmöglichkeiten bei Offshore-Arbeitsplätzen sind deutlich eingeschränkt. Daraus ergeben sich besondere Anforderungen und Bedingungen für die Eignungsuntersuchung und Betreuung der Mitarbeiter/innen, die diese Anlagen im Hochseebereich errichten, betreiben und warten. Von der Deutschen Gesellschaft für Maritime Medizin e. V. wurde - in Anlehnung an bestehende Regelungen - eine DGMM-Empfehlung für die Eignungsuntersuchung auf deutschen Offshore-Anlagen erstellt.

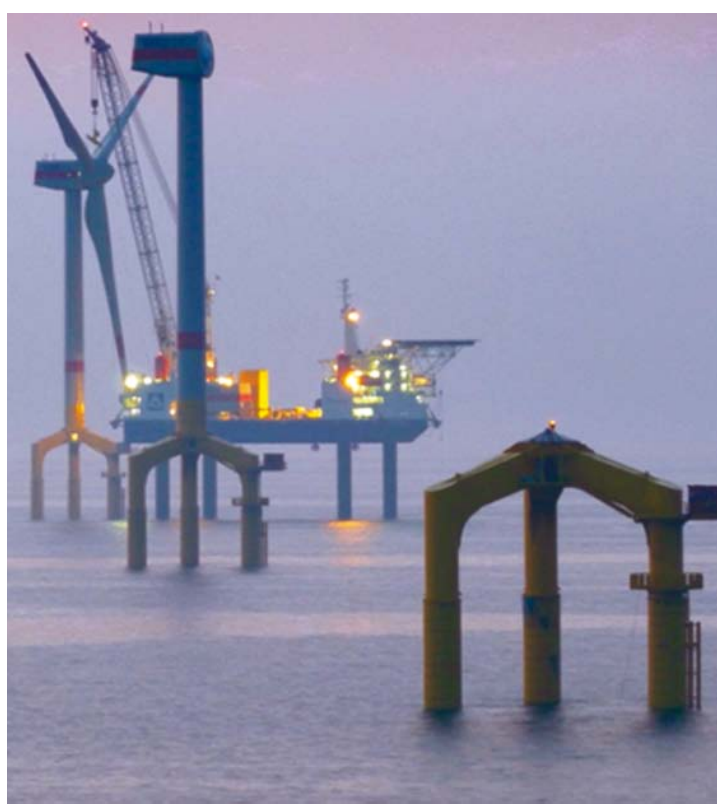

Der Workshop wendet sich an alle in dieser Branche Tätigen, insbesondere an Arbeitsmediziner.

Veranstalter: VGB Power Tech e.V. in Zusammenarbeit mit der DGMM

Veranstaltungsort: Ostfriesisches Landesmuseum Emden,

Rathaus Rummel, Brückstr. 1, 26725 Emden

Teilnahmegebühr: 200 Euro

Weitere Informationen und

Anmeldung: VGB-Geschäftsstelle,

Gerda Behrendes

Postfach 1039 32,

45039 Essen

Tel.: 0201 8128-313,

Fax: 0201 8128-364,

gerda.behrendes@vgb.org 